\title{
Study on the Dissemination of Gannan Hakka Folk Songs from the Perspective of Inter-subjectivity
}

\author{
Miao Huang \\ Jiangxi Science and Technology Normal University \\ Nanchang, China
}

\begin{abstract}
This paper focuses on the relationships between "field and stage", "disseminator and recipient" and "single and multiple" in the dissemination process of Gannan Hakka folk songs from the perspective of "inter-subjectivity", and proposes to break the relationships between subject and object in the three relations, eliminate barriers to achieve equality, interaction and communication, so as to promote the dissemination and inheritance of Gannan Hakka folk songs.
\end{abstract}

Keywords-inter-subjectivity; field and stage; disseminator and recipient; single and multiple

\section{INTRODUCTION}

Inter-subjectivity is a methodology of modern philosophy based on the development of traditional philosophy. It emphasizes the stipulation in the relationship among subjects, that is, "mutual understanding" and "consensus" between subjects. "Mutual understanding" refers to the understanding and recognition among subjects, while "consensus" refers to the integration and common characteristics among subjects formed by the mutual understanding toward the same thing of different subjects. Inter-subjectivity breaks the dualism of subject-object opposition in traditional philosophy, focuses on the relationship between "ego-subject" and "objective subject", and emphasizes their relevance and unity, and it is the dialogue and communication between ego-subject and objective subject, changing the isolated individual subject into the interactive subject. This methodology provides an important philosophical basis for clarifying the three relations between "field and stage", "disseminator and recipient" and "single and multiple" in the process of spreading Hakka folk songs in Gannan.

\section{THE BETTER: "FIELD" OR "STAGE"}

Gannan Hakka folk songs are rooted in the field work, festivals and daily life of the Hakka people. There are folk songs that reflect Hakka people's life and customs like "Chui Kai Meng Wu Kan Jiao Lian", "Sister cannot Leave Her Brother", "Da Zhi Shan Ge Guo Heng Pai", etc., as well as lamp songs that singing during the lantern festivals on New Year's Day or other festivals like "Banjiu Diao", "Song Lang Diao", "Peony Diao", etc. There are songs with relatively fixed melody and lyrics, such as "Song Lang Dang Hong Jun", "Zhu

Project: This paper is one of the achievements of the "13th Five-Year" (2016) social science project of Jiangxi province, the "Research on Gannan Hakka Folk Songs from the Perspective of Music Communication" (No. 16YS10)..
Pian Ge", "Diu Da Diu", etc., as well as bold and unconstrained work songs such as "Chuan Gong Chant", "Mu Pai Chant", "Xiu Qiao Chant", and so on. Gannan Hakka people sing whenever they are happy, sad, working and celebrating festivals, expressing their true feelings through their songs in the primary ecological environment. Singing folk songs freely on the stage of life has strong local characteristics, which is not only art, but also life! Therefore, the rural field is the main area for the survival of Gannan Hakka songs. As said by Qiao Jianzhong, "folk songs are the classics of farming culture, which essence is improvisation ... The singing of original folk songs is like birds flying in the sky and fish in the water. The stage is the country field, and it would lose the original taste if it is over packaged for a competition.

What is the role of another field --- "stage" in the spreading of Gannan Hakka folk songs? Does it form the two dimensional fields opposite to "field"? Starting from the principle of "inter-subjectivity", some scholars believe that folk songs come from life and should go back to life. Stage folk songs on the stage are artificial and without soul. The "entertaining others" and "stylization" performance of staged folk songs is different from the "self-entertaining" and "improvisation" singing of the original folk songs. It has "weakened the regional characteristics and gradually made primitive folk songs lose its unique singing style and special aesthetic connotation, and its particular art charm." Therefore, the country field is the only "subject" field of all folk songs.

But when we look at both of them with inter-subjectivity, we get another conclusion. With the changes of the times, it has become common for folk songs going out of the countryside and moving to the urban stage. At the stage of "Folk Song, China" and "Chinese Folk Songs", the singing of Hakka singers in Gannan makes more people know and understand Gannan Hakka folk songs and Hakka life, which have a positive and far-reaching significance for the promotion of Gannan Hakka folk songs. Although the stage is not a village field and without the fragrance of soil, "the staged folk songs reproduce the primitive condition of a certain historical period through stage design and bring life to the original folk songs. At the same time, they have the reference significance to the original folk songs in the aspects of strong tension and strict structure." Therefore, "stage" plays an important role in the spreading of Hakka folk songs in southern Jiangxi province. In fact, the "field" and "stage" are not antagonistic relations, and both of them have different effects on Gannan Hakka folk 
songs. The "field" provides the ecological environment for the survival of folk songs, which is the vertical inheritance of Gannan Hakka folk song culture. The "stage" provides the positive promotion platform for folk song culture, which is the horizontal spreading of Gannan Hakka folk song culture. Art comes from life and will nurture life in response. The field and stage depend on each other and promote each other. The stage cannot do without the rustic simplicity of the field, while the field cannot do without the boutique processing of stage.

\section{THE SUBJECT: DISSEMINATOR OR RECIPIENT}

The spreading-receiving relationship is the relationship between dissemination subject and receiving subject in the structure of dissemination, and it is the most important relationship in dissemination. Zheng Xingdong believes that spreading-receiving relationship is the product of the interaction between disseminator and recipient. The spreadingreceiving relationship has two aspects, the role relationship and information relationship between dissemination and reception. The essence of spreading-receiving relationship is the satisfaction between disseminator and recipient. Therefore, in the spreading of Gannan Hakka folk songs, what is the relationship between "disseminator" and "recipient"? How does the two affect and influence each other?

From the perspective of "inter-subjectivity", both "disseminator" and "recipient" are the main subjects in the spreading of Gannan Hakka folk songs. The two exist in the inter-subjective way and constitutes the relationship between subjects. First of all, the two subjects are different and exist simultaneously. Broadly speaking, "disseminators" in the spreading of Gannan Hakka folk songs not only include the native primitive singers, but also the "academic" singers that sing Hakka music, as well as research institutions and scholars engaged in the research in this field. However, "recipients" are the people that receive these messages. From the perspective of "inter-subjectivity", disseminator and ordinary people coexist in the process of the spreading of Gannan Hakka folk songs in the existence mode between subjects. But the "subjectivity" of the two is different. The subjectivity of disseminator is reflected in the freedom of choosing songs and being able to improvise, and thus he has the characteristics of initiative, leading and creativity. However, the subjectivity of recipient is reflected in choosing freely whether to accept Gannan Hakka folk songs and the acceptance degree, and thus he has the characteristics of demanding and power subjectivity. In addition, the two subjects interact and influence each other. The "disseminator" and "recipient" of Gannan Hakka folk songs is a two-way interactive process. At the cognitive level, the disseminator correctly deals with the needs of the recipient; from the attitude level, the recipient is equal with recipient; at the position level, the disseminator changes position with recipient; at the action level, disseminator lets recipient participate reasonably; at the spiritual level, disseminator cultivates the correct watching and hearing attitude of recipient. However, the aesthetic orientation and individual needs of the recipients affect the path and content of the spreading of Gannan Hakka folk songs. With the rapid development of the information age, the traditional single folk songs spreading path has been unable to meet the requirements of the times, nor the needs of the recipients. In order to realize the effective spreading, the disseminator must make some changes. At the same time, with the change of audience's aesthetic taste, the songs and forms of singing also need to be adjusted. Therefore, in the perspective of inter-subjectivity, both are the main subjects of Gannan Hakka folk songs. They are equal. Only when the two subjects reach an agreement and understand each other can better promote the effective spreading of Gannan Hakka folk songs.

\section{The MaINSTREAM: "SingLE" OR "MUlTIPLE"}

Gannan Hakka folk songs were born and grew in Hakka. Before the destroying of the "ecological environment" and "ecological demand" that in conformity with it, these songs have been simply spread by oral teach in the original ecological inheritance mechanism of the local people. The single and primitive way of inheritance preserved the simplicity and purity of the traditional Hakka folk songs in Gannan.

However, under the huge impact of information and globalization, the inheritance and transmission of Gannan Hakka folk songs have changed greatly in the context of "media is message". The traditional single oral teaching mode is gradually broken, and the appearance of multi-media has changed the inheritance and spreading method of Gannan Hakka folk songs. In addition to make traditional Gannan Hakka folk songs be spread in a wider and broader scope, it also makes the traditional folk songs lose the simple, rough, full of the original taste vitality and artistic charm. Therefore, the inheritance and development of Gannan Hakka folk songs is continue to maintain the "single" spreading mode to retain its true color, or obtain its survival with the help of multiple modes of transmission.

Lai Guangchang pointed out that "in addition to the basic characteristics of culture, the primitive folk songs also have the following five characteristics: first is natural, without artificial processing; second is spontaneity, without interference from outside forces; third is folk nature, born and exist in the folk; fourth is uniqueness, with distinctive regional color; fifth is steady inheritance, although the times is changing, the main characteristics remain unchanged." In order to comply with the above characteristics, Gannan Hakka folk songs should ensure the "ecological environment" of the survival first. However, what is the fact? The formation and characteristics of Hakka folk songs in southern Jiangxi Province have typical geographical impression. From content to music form, the formation and evolution are inseparable from the local geographical and ecological environment. The geographical condition provides conditions, backgrounds and possibilities for the formation of folk songs, and Folk songs also integrate with geography and ecology, and become part of regional culture. "Without mountain, there are no Hakka people. And all Hakka people live around the mountain". Hakka people live in mountainous areas, so the singing of Hakka folk songs is loud and sonorous, bold and unconstrained. Also because of these geographical characteristics, there are many labor chants related to woods in Gannan Hakka folk songs like Famu chant, Mupai chant, Chuangong chant, etc. However, with the process of urbanization, the Hakka people's production and 
lifestyle have undergone tremendous changes. People living in the mountains have been out of the mountains. The change of "ecological environment" influences the ecological demand of Hakka people toward Hakka folk songs. People out of the mountains no longer need to use folk songs to encourage themselves, nor to communicate or express personal feeling. At the same time, the cutting and transportation of woods is replaced by machines, and thus work chants gradually die out. But some popular tunes and lantern song related to Gannan Hakka folk activities have survived well because of the folk customs. However, under the impact of diversified culture, how far can the traditional Hakka folk customs go?

Obviously, the "single" spreading mode can maintain the original flavor of Gannan Hakka folk songs to the maximum extent; however, it is not conducive to its development because it emphasizes the closeness of its space. As a kind of culture, if folk songs are not improved with the times, they will inevitably be eliminated by history, on the verge of disappearance. The inheritance of folk songs needs the singing! Therefore, in addition to maintain the "originality" of folk songs, it also needs the using of traditional media and modern media and other means to expand the spreading scope and influence of Gannan Hakka folk songs to achieve the "diversification" spreading. "In the traditional heritage expression, oral spreading itself presents the characteristics of openness and arbitrariness, which was abolished in the age of the text and electronic media. The expression of cultural heritage is considered with closure that whether in traditional media or in film, photography, this statement is placed to within a relatively closed space according to a certain reason." The inheritance of Gannan Hakka folk songs culture not only needs the traditional dissemination mode, but also should use the network media to break through the seal of Gannan Hakka folk songs, so as to enhance the influence, which would play a better spreading effect on the folk songs. Of course, the "multiplied" dissemination focuses on spreading, rather than inheritance. Therefore, "being transplanted" and "being performed" should not be the mainstream of spreading and inheritance. As said by McLuhan, "Today, we want to see the direction in our culture, and it's necessary to keep a distance from the bias and pressure generated by a certain form of technology". The inheritance and development of folk songs need to be placed in the soil of folk songs, and the coexistence of "single" and "multiple" spreading modes is needed.

\section{CONCLUSION}

In conclusion, Gannan Hakka folk songs, like other original folk songs in our country, are in the dilemma of how to keep their colors while passing down. From the perspective of "inter-subjectivity", the spreading mode of emphasizing both "field" and "stage", centered on "disseminator" and "recipient" and considering "single" and "multiple" can positively promote the inheritance and dissemination of Gannan Hakka folk songs to the largest extent.

\section{REFERENCES}

[1] Huang Yuying. Research on Hakka Folk Songs in Jiangxi, [M]. Beijing: China Federation of Literature and Art Press, 2006.11
[2] Wang Xiaodong. Critique of Intersubjectivity Theory in Western Philosophy, [M]. Beijing: China Social Sciences Publishing House, 2004.12

[3] Huang Yunzhen. Collision and Transformation-The Waning of the Traditional Transmission Carrier of Primitive Folk Songs, [J]. Music art Journal of Shanghai Conservatory Of Music, 2006 (2)

[4] Pi Xiaocai. My Opinion on the Survival of Chinese Original Folk Songs, [J]. Explorations In Music, 2006 (1)

[5] Liu Hui. Protection and Dissemination of Primitive Folk Songs, [J]. China Music Education, 2008 (6)

[6] Zhang Xia. The Contemporary Rise and Spread of Primitive Folk Songs, [J]. Musical Creation, 2012 (1) 